\title{
Barriers and Facilitators to Identify and Discuss Depression and Anxiety in Visually Impaired Adults: A Qualitative Study on the Service User's Perspective
}

Edine P.J. van Munster ( $\nabla$ e.vanmunster@amsterdamumc.nl )

Amsterdam UMC, Vrije Universiteit Amsterdam, Amsterdam Public Health Research Institute Hilde P.A. van der Aa

Amsterdam UMC, Vrije Universiteit Amsterdam, Amsterdam Public Health Research Institute

Peter Verstraten

Robert Coppes Foundation

Ruth M.A. van Nispen

Amsterdam UMC, Vrije Universiteit Amsterdam, Amsterdam Public Health Research Institute

\section{Research Article}

Keywords: Vision loss, Visual impairment, Depression, Anxiety, Detection

Posted Date: April 20th, 2021

DOI: https://doi.org/10.21203/rs.3.rs-418059/v1

License: (c) (i) This work is licensed under a Creative Commons Attribution 4.0 International License.

Read Full License

Version of Record: A version of this preprint was published at BMC Health Services Research on July 28th, 2021. See the published version at https://doi.org/10.1186/s12913-021-06682-z. 


\section{Abstract}

Background. Depression and anxiety are highly prevalent, but often unrecognized in adults with visual impairment $(\mathrm{VI})$. The purpose of this study was to explore service users' views on facilitators and barriers in identifying and discussing mental health problems in adults with VI.

Methods. Semi-structured interviews, based on the Integrated Model for Change, were conducted with 16 service users from three Dutch low vision service organizations. Interview data was analyzed using the framework approach.

Results. Prominent themes in service users' cognitions and skills were their focus on VI, lack of health literacy, misattribution of symptoms and difficulties in acknowledging their VI and mental health problems. Informal and formal support were seen as facilitators. However, participants mentioned the need of improving healthcare providers' knowledge, skills and attitude to increase the likelihood of detection and communication about depression and anxiety.

Conclusion. Our findings suggest that, compared to barriers experienced in general population, adults with VI face additional barriers in identifying and discussing mental health problems, partly caused by their impairment and increased vulnerability. Healthcare providers and social support systems seem essential for them in reducing these barriers. However, there might be a mismatch between service users' needs and healthcare providers' knowledge, skills and attitude. Training healthcare providers may improve detection of depression and anxiety in adults with $\mathrm{VI}$.

\section{Introduction}

About one third of adults with visual impairment experience subthreshold symptoms of depression and/or anxiety $(1,2)$, indicating clinically significant symptoms but no actual disorder. These prevalence estimates are significantly higher compared to the general population (1). In adults with VI, having (subthreshold) depression can lead to decreased health-related and vision-related quality of life and visual functioning (3). An early treatment approach is recommended to reduce negative influences on quality of life.

Despite effective mental health treatments available for people with $\mathrm{VI}(4)$, more than half do not receive any mental health support (5-7). Different barriers for receiving treatment are expressed by adults with VI. A former study showed that they often experience a lack of knowledge about symptoms and treatment possibilities, followed by not wanting to rely on others (5). Symptoms of depression and anxiety seem to be systematically overlooked by adults with VI themselves, but also by others.

Healthcare providers often do not recognize depression in visually impaired adults. From the perspective of healthcare providers, this may be due to their focus on physical health instead of psychological health (8). A lack of confidence in their own knowledge and skills seems to limit them in identifying symptoms of depression in service users (9). Other examples of barriers experienced by healthcare providers are lack 
of training in recognizing depression, absence of standard procedures within their organizations to detect depression, limited time and high workload $(8,10)$. Moreover, many healthcare providers believe service users themselves create barriers: denial and a defensive attitude are the most common barriers mentioned (8). Healthcare providers believe reluctance to discuss depression might be due to difficulties in communication, social stigma related to depression, or perceived negative consequences of acknowledging depression $(8,9)$.

While a few studies investigated barriers from the healthcare providers' perspective, so far, no in-depth research has been performed to explore the perspective of adults with VI. In addition, previous research focused on detection of depression, leaving anxiety underexposed, while prevalence estimates of anxiety are high as well (1). Therefore, this study aimed to explore the process of identifying and discussing depression and anxiety from the service users' perspective. Barriers and facilitators that contribute to the identification and discussion are determined, with special attention on the healthcare provider's role.

\section{Methods}

\section{Study design and participants}

Adults with VI (18 years or older) and (a history of) symptoms of depression and/or anxiety were recruited to participate in this qualitative study. A heterogenous group of adults with VI with varying eye diseases, age and gender was included, for participating in semi-structured interviews. The six-item screener, a short version of the Mini Mental State Examination, was used to measure participants' cognitive abilities (11). Adults with severely impaired cognitive abilities (scores lower than three on the six-item screener) or minimal understanding of the Dutch language were excluded from participation. Participants were purposively recruited from three Dutch low vision service organizations. Psychologists were asked to select eligible service users, approach them by telephone or during face-to-face meetings, offer them a written information letter and informed consent form, and answer questions if applicable. All participants provided written consent. One participant who consented to participate dropped out due to declining mental health.

\section{Data collection}

Semi-structured face-to-face interviews with individual service users were performed by the first author (EvM), who worked as a researcher at one of the low vision service organizations, but had no prior relationship with the participants. Interviews were conducted at the participant's home, except for two interviews that were conducted at the low vision service organization. Participants were allowed to bring a trusted person to the interview, which occurred during two interviews. Interviews lasted between 27 and 85 minutes (mean $=64$ minutes), were audio-recorded and transcribed verbatim. The interviewer recorded observations about the participant's ability to reflect on their own situation.

\section{Theoretical Framework}


The Integrated model for Change (e.g. the I-Change model) was used as a theoretical framework to develop the interview guideline (Additional file 1), and to analyze barriers and facilitators for the detection and discussion of depression and anxiety. The I-Change model is an integrative model using several scientific models about social cognition, and explains motivational and behavioral change (12). I-Change is often used in research about healthcare utilization from various perspectives $(13,14)$. According to the I-Change model, behavior is the result of predisposing, environmental, awareness and motivational factors.

\section{Analyses}

Thematic analysis of the interview data was performed to describe and understand barriers and facilitators. I-Change model determinants were used as the coding framework (15). All analyses were performed by two researchers (EvM, HvdA) using Atlas.ti8 software. The first step of analyzing the interview data involved open coding to help the researchers get familiar with the data. Several interviews were coded and consensus was reached, based on which the codebook was developed. Second, the codebook was used to analyze all interviews. Third, codes were clustered into subthemes. It was concluded that the last interview lacked new subthemes indicating that data saturation may have been reached. Subsequently, subthemes were summarized into main themes and assigned to domains based on consensus between the two researchers.

\section{Results}

Sixteen service users (44\% male) participated in this study. Mean age was 60 years and ranged between 33 and 91 years. Participants' medical files showed different diagnoses as cause of their VI (Table 1). In six participants comorbidities, such as hearing loss, autism spectrum disorder or physical complaints, were present. 
Table 1

Participant characteristics $(N=16)$

\begin{tabular}{|llll|}
\hline Characteristic & $\mathbf{N}(\%)$ & Mean (SD) & Median [range] \\
\hline Sex: male & $7(43.8 \%)$ & & \\
\hline Age (in years) & & $59.8(14.4)$ & $58.0[33-91]$ \\
\hline Acquired VI (age of onset) & $12(75.0 \%)$ & $40.5(20.5)$ & $35.5[12-78]$ \\
\hline Blind & $12(75.0 \%)$ & \\
\hline Symptoms of depression in the past & $13(81.3 \%)$ & \\
\hline Symptoms of anxiety in the past & $7(43.8 \%)$ & \\
\hline Current symptoms of depression/anxiety & $5(31.3 \%)$ & \\
\hline Eye disease $\quad$ Retinal detachment & $4(25.0 \%)$ & \\
\hline & Optic nerve disease & $4(25.0 \%)$ & \\
\hline & Macular degeneration & $3(18.7 \%)$ & \\
\hline & Other retinal disease & $3(12.5 \%)$ & \\
\hline & Other & $2(43.7 \%)$ & \\
\hline SD standard deviation, VI visual impairment \\
\hline
\end{tabular}

\section{Barriers and facilitators}

Main themes and subthemes identified through the inductive process were mapped to domains within the I-Change model. These were: 1) personal factors, 2) environmental factors, 3) awareness related factors, and 4) motivational factors. Two domains were added based on the input that was gathered: 5) social support system and 6) healthcare provider's role. Table 2 represents all facilitators and barriers gathered within these domains, their themes and sub-themes. 
Table 2

Themes and sub-themes in detection and discussion of (subthreshold) depression and anxiety

\begin{tabular}{|c|c|c|}
\hline Domain & Theme & Sub-theme \\
\hline \multirow[t]{3}{*}{ 1. Personal factors } & \multirow[t]{3}{*}{ Coping } & - Coping strategies $(+,-)$ \\
\hline & & - Internal locus of control $(+,-)$ \\
\hline & & - Personality traits $(+,-)$ \\
\hline \multirow{4}{*}{$\begin{array}{l}\text { 2. Environmental } \\
\text { factors }\end{array}$} & Acquired care & - Receiving care $(+,-)$ \\
\hline & \multirow[t]{3}{*}{ Social inclusion } & - Experiences with low vision services $(+,-)$ \\
\hline & & - Stigma related to VI (-) \\
\hline & & - Lack of equality (-) \\
\hline \multirow{8}{*}{$\begin{array}{l}\text { 3. Awareness } \\
\text { related factors }\end{array}$} & Risk perception & - Impact VI on mental health $(+,-)$ \\
\hline & Detection & - Perceived severity $(+,-)$ \\
\hline & \multirow[t]{6}{*}{ Knowledge } & - Need for help $(+,-)$ \\
\hline & & $\begin{array}{l}\text { - Recognition of psychological complaints or } \\
\text { changes in behavior }(+)\end{array}$ \\
\hline & & - Focus on $\mathrm{VI}(-)$ \\
\hline & & - Misattribution of symptoms (-) \\
\hline & & - Knowledge of mental health interventions (-) \\
\hline & & - Abilities to collect information (-) \\
\hline \multirow{4}{*}{$\begin{array}{l}\text { 4. Motivational } \\
\text { factors }\end{array}$} & Attitude & - Attitude towards discussion $(+,-)$ \\
\hline & \multirow[t]{3}{*}{ Willingness to discuss } & - (Dis)advantages of discussion $(+,-)$ \\
\hline & & - VI complicates discussion(-) \\
\hline & & - Self-confidence on discussion $(+,-)$ \\
\hline \multirow[t]{4}{*}{$\begin{array}{l}\text { 5. Social support } \\
\text { system }\end{array}$} & $\begin{array}{l}\text { Informal emotional } \\
\text { support }\end{array}$ & $\begin{array}{l}\text { - Recognition and discussion by social support } \\
\text { system }(+,-)\end{array}$ \\
\hline & \multirow[t]{3}{*}{ Network size } & $\begin{array}{l}\text { - Guidance and encouragement from social } \\
\text { support system }(+,-)\end{array}$ \\
\hline & & $\begin{array}{l}\text { - Indifference and incomprehension impact VI on } \\
\text { mental health }(-)\end{array}$ \\
\hline & & - Number of social contacts $(-)$ \\
\hline
\end{tabular}




\begin{tabular}{|lll|}
\hline Domain & Theme & Sub-theme \\
\hline $\begin{array}{l}\text { 6. Healthcare } \\
\text { provider's role }\end{array}$ & $\begin{array}{l}\text { Focus of healthcare } \\
\text { provider }\end{array}$ & $\cdot$ Focus on practical rehabilitation VI $(-)$ \\
& $\begin{array}{l}\text { Formal support } \\
\text { Expertise of healthcare } \\
\text { provider }\end{array}$ & $\begin{array}{l}\cdot \text { Attention impact VI on mental health }(+,-) \\
(+)\end{array}$ \\
& $\cdot$ Discuss mental health/current symptoms $(+,-)$ \\
& $\cdot$ Help-seeking $(+,-)$ \\
& $\cdot$ Transfer knowledge $(-)$ \\
& $\cdot$ Knowledge healthcare provider $(-)$ \\
& $\cdot$ Skills healthcare provider $(-)$ \\
& $\cdot$ Attitude healthcare provider $(-)$ \\
& $\cdot$ Relationship with service user $(+)$ \\
\hline
\end{tabular}

\section{Visual Impairment, + facilitator, - barrier}

\section{Personal factors}

Participants used various ways to cope with their mental health problems. More than half of them mentioned a passive or ineffective coping strategy, such as denial and overcompensation. Active problem solving was addressed as an often used coping strategy by a few participants. Some of them felt the need to solve their problems by taking the initiative to ask for help, most often from general practitioners (GPs), while others tried to solve their problems relying on their own resources.

\section{Environmental factors}

A few participants mentioned that receiving care from low vision service organizations increased their likelihood of discussing depression or anxiety, in any stage of the symptoms, just because they had access to a healthcare provider. In addition, having a VI changed some participants' perspectives on social inclusion due to perceived stigma and an experienced lack of equality. They felt that their VI made them different, vulnerable and unequal to others, and that discussing mental health problems would increase those feelings. One participant mentioned: "I feel like they are looking down on me, because I am already different from everyone else. (...) If I can just participate in society in a normal way or if everyone sees me as a normal person, that is already so different. Then mental health problems become less uncomfortable and more negotiable (female, aged 41, blind)."

\section{Awareness}

After discussing mental health, participants believed that $\mathrm{VI}$ increased their feelings of being vulnerable and inferior to others. In their opinion these feelings and permanent loss, or future losses in progressive 
eye diseases, caused their mental health problems. One participant explained: "Vision loss is bigger than just losing your sight. There is so much more you can't do anymore, which makes you feel worthless and changes you as a person (female, aged 49, blind)." However, in the beginning almost all participants focused on the practical implications of their $\mathrm{VI}$, and therefore failed to acknowledge its impact on their mental health. In addition, half of the participants mentioned misattribution of symptoms limited their recognition. They thought symptoms such as having low energy, physical complaints and having less interest in activities were related to their old age, their personality, medicines they used, a previous accident or their $\mathrm{VI}$ instead of acknowledging them as mental health problems. After a while, they became aware of the significant impact of the VI on their mental health and often identified the VI as the cause of their mental health problems.

Being unaware of possibilities for receiving mental health support was often mentioned as a barrier for discussing symptoms, especially within low vision service organizations. Two participants still lacked knowledge about where to find appropriate care. Some participants explained that their reduced ability to collect visual information may have caused this lack of knowledge: "The general practitioner's waiting room is full of posters. If you are a good sighted person waiting, you can look around and can be triggered to investigate a subject further on the internet. As a blind person you just happen to hear it or need to think of it yourself (female, aged 41, blind)." Because of the decreased ability to receive and collect information, participants stressed the importance of healthcare providers to provide appropriate information on the increased risk of depression and anxiety in people with $\mathrm{VI}$, and on possibilities for support.

\section{Motivation}

Both advantages and disadvantages of discussing feelings of depression and anxiety with a healthcare provider emerged. The prospect of receiving support was mentioned as an advantage. Participants felt that tailored support could help them comprehend and improve their situation, and help them feel in control again. Disadvantages included fear of further deterioration of mental health by discussing it, fear of potential changes in daily life, and the need to acknowledge their VI. One participant explained: "The moment I was going to discuss it with a psychologist, I had to admit something was wrong. I miss something (vision) and I have to adjust my life accordingly. I wasn't ready until last year (female, aged 47, blind)."

Participants often considered their VI made discussing mental health with a healthcare provider more difficult. Several of them indicated that their VI made it difficult to open up about their mental health problems, because they had to acknowledge their disability and deal with its consequences. Also, they had to open up about two subjects that made them feel vulnerable. One participant mentioned VI could also decrease trust in others, because it limits interpretation of body language. Another participant referred to having depression as an extra burden on top of his Vl: "People without vision loss do not struggle with a visual impairment. Therefore, they have the capacity and time to put energy in other things, like feelings of depression (male, aged 33, blind)." 


\section{Social support system}

Informal emotional support was indicated as a significant facilitator in identifying and discussing depression and anxiety. More than half of the participants felt guided by a loved one, who helped them to recognize the symptoms of depression or anxiety, and encouraged them to discuss it with a healthcare provider. However, some participants lacked informal support or received more practical solutions, e.g. write feelings down or get a guide dog. Some of them also expressed their loved ones' incomprehension of the impact of VI on mental health: "It was the beginning of us growing apart. She (partner) literally shrugged her shoulders and said 'You'll get over it.' As if it were a common cold (male, aged 56, blind)." One participant mentioned that $\mathrm{VI}$ could limit the size of the service user's social network due to loss of daily activities (e.g. losing their job or decrease in social activities), and therefore might leave them with fewer people that are able to provide informal support.

\section{Healthcare providers}

Participants expressed the importance of the healthcare provider's role in their recognition and willingness to discuss symptoms. They mentioned that ophthalmic personnel and GPs not often linked the VI with mental health problems and almost never discussed mental health. Nevertheless, participants were positive about their referrals to low vision service organizations, because they expected healthcare providers with knowledge of VI would understand their situation. However, only half of the participants mentioned a healthcare provider discussed mental health after referral, and if discussed, always by social workers or counsellors. In addition, low vision service workers often focused too much on the practical side of low vision rehabilitation and had little attention for the impact of VI on mental health. "VI definitely has an impact. Actually, there are institutions that can help you deal with using an iPad or they tell you that you can no longer drive a car. But in that case your state of mind is ignored (male, aged 80, low vision)."

Participants mentioned that healthcare providers should have a constant focus on possible mental health problems in people with $\mathrm{VI}$, from the first diagnosis until the end of rehabilitation, and anticipate on mental difficulties in the future. Ophthalmic personnel and GPs should be aware of both the physical and emotional impact of $\mathrm{VI}$, and the opportunities for support. Participants stressed the importance of followup care to see how the service user is doing, and referrals to low vision service organizations in an early stage. "I think when ophthalmologists diagnose permanent vision loss, it should trigger them to start providing care (male, aged 64 blind)." Participants recommended that healthcare providers invite them to talk about mental health problems and transfer their knowledge about different aspects of depression and anxiety in relation to the $\mathrm{VI}$, such as prevalence rates, possible symptoms that may be experienced and opportunities for receiving support.

However, participants thought that healthcare providers, especially GPs, often lacked knowledge, skills, expertise and the proper attitude to detect and discuss depression and anxiety. In addition, GPs and ophthalmic personnel seem to be unaware of the impact of VI on mental health, and have difficulty referring service users to the appropriate care. According to service users, low vision service personnel 
tended to have difficulty linking the impact of $\mathrm{VI}$ with mental health problems as well. Overall, healthcare providers tended to have difficulties recognizing symptoms of depression and anxiety and seemed to lack confidence and skills in empathizing with service users concerning these symptoms. Moreover, participants assumed a lack of critical attitude in healthcare providers because they often focused on practical solutions regarding $\mathrm{VI}$, and occasionally trusted service users' statements about having a good mental health too easily. Therefore, participants proposed that healthcare providers consider complaints as an aspect of depression or anxiety, and integrate mental health in their routine care, for example by using a screening instrument. "A general practitioner should check some things in adults with visual impairment by default, such as energy, activities and mood. Ask how everything is going and if necessary: provide a referral (male, aged 33, blind)." Finally, participants indicated a longer, persistent, equal and trustworthy relationship with their healthcare provider as facilitating. According to participants, healthcare providers can establish this by sharing personal stories and considering themselves equal to service users.

\section{Discussion}

The aim of this study was to explore facilitators and barriers in the detection and discussion of depression and anxiety in adults with VI. Based on interviews with service users, this study uncovers several important facilitators and barriers regarding service users' cognitions and skills, social support networks and the influence of healthcare providers. These factors are in accordance with the determinants of the I-Change model.

Service users acknowledge that depression and anxiety are highly prevalent in people with VI. However, they seem to encounter difficulties in acknowledging their own mental health problems and VI. This refusal to acknowledge VI may be part of someone's grieving process and may aggravate feelings of depression and anxiety. People with VI can be recurrently confronted with their loss, because new situations and new problems keep redefining their loss (16), for instance not being able to see their newborn grandchild. This suggests that adults with VI need to adapt to and acknowledge, their VI repeatedly during their lives. Healthcare providers should be aware of these reoccurring confrontations with loss of vision that can cause mental health problems.

Being visually impaired may limit service users to open up about mental health problems, because of increased feelings of vulnerability and decreased trust in others. Previous studies confirm that adults with VI often experience difficulties in opening up about mental health problems and sometimes even deny psychological distress $(17,18)$. Many service users experience self-stigma on both $\mathrm{VI}$ and mental health problems, which may exacerbate these difficulties. Self-stigma may prevent them from seeking help and receiving treatment $(19,20)$. Self-stigma can potentially be reduced by providing psychoeducation (21). This emphasizes the importance of healthcare providers discussing mental health problems related to $\mathrm{VI}$ (e.g. "it is not surprising that you experience these symptoms, as many other adults with VI do"). 
In addition, people with VI seem to experience difficulties in identifying their mental health problems. Some indicate this is due to limited knowledge about the impact of VI on mental health and treatment possibilities. Especially in this population lack of knowledge seems to be experienced as a barrier for help-seeking (5), since it is less often mentioned in the general population $(22,23)$. This may be caused by the limited abilities of people with $\mathrm{VI}$ to obtain processable information, which can lead to low health literacy $(24,25)$, i.e. the ability to "obtain, process and understand basic health-related information and services to make appropriate health decisions" (26). Health literacy seems an important facilitator in helpseeking for mental health problems (27). People with VI might face specific barriers in obtaining healthrelated information because it is inaccessible (e.g. posters in a waiting room or information on a website). This emphasizes the importance of using accessible and tailored ways of informing people with VI on mental health problems and treatment possibilities, e.g. during contacts with an experienced healthcare provider or via audio recordings on a website.

Another important reason for difficulty in identifying mental health problems may be a misattribution of symptoms. Some symptoms of depression and anxiety, such as loss of daily activities, poorer self-care and fatigue, are often seen in people with vision loss (28-30), but can also be symptoms of mental health problems as they are highly prevalent in this population. Informing service users about the high prevalence of mental health problems in people with VI in a timely manner is warranted.

An active problem solving coping strategy seemed to assist service users in being able to discuss symptoms with a healthcare provider. However, from the literature we know that especially service users with an avoidant coping style seem to experience mental health problems (31) and people with mental health problems seem to have more difficulty in using adaptive coping strategies (32). Therefore, these service users seem to be more dependent on others, i.e. informal and formal support systems, in being able to discuss mental health symptoms.

Service users often mentioned informal support helped them to recognize and discuss mental health problems. In adults with VI this support from loved ones seems to be even more important, because they often report a loss of control, low self-esteem and increased dependency on others for many daily activities (33-35). Informal support consists of instrumental support (e.g. assisting with tasks of daily living) and emotional support (e.g. affective support) (36). Strong informal emotional support is associated with help-seeking in mental health problems (37). However, adults with VI more often receive instrumental support than emotional support, and most often responsibilities for providing support lies with their family members (38). Service users experienced different levels of emotional support, that may be explained by adaptation to vision loss. Vision loss is associated with possible isolation from the family, changes in roles and responsibilities between family members, and burden within family members (39-41). Therefore, some social support networks might have focused on providing instrumental support or had limited resources to provide emotional support.

Healthcare providers could help service users to identify and discuss mental health problems. It seems important that healthcare providers understand the impact of VI on mental health, start a conversation 
about mental health and share knowledge about prevalence and symptoms of mental health problems. A previous study in women with VI confirms healthcare providers' importance in service users achieving health literacy (24). However, healthcare providers often seem to focus on $\mathrm{VI}$, which is consistent with previous studies (8). Service users also expressed the need of receiving information about the impact of VI on mental health and sometimes questioned the expertise (e.g. knowledge, skills and attitude) of healthcare providers. Nevertheless, only a quarter of ophthalmic and low vision service personnel provides education and information for suspected depression (10). In addition, they often report a lack of confidence in knowledge and skills as barriers to depression management in adults with $\mathrm{VI}(9,10)$. These barriers may have limited healthcare providers in providing information about mental health and treatment options, but also in starting a conversation about depression or anxiety. A possible explanation for the lack of critical attitude might be that healthcare providers think service users are often reluctant to discuss mental health $(8,9)$. Therefore, there might be a mismatch between the service users' needs and healthcare providers' abilities, resulting in underrecognition of mental health problems.

\section{Strengths and limitations}

A first strength is that this study describes potential barriers and facilitators from the perspective of adults with VI. The qualitative design allows us to understand the actual experiences of this fragile population in discussing this highly prevalent problem. Second, the I-Change model turned out to be valuable to create a comprehensive interview guide. Third, a heterogeneous group of adults with VI from different gender, age groups and with various ophthalmic diagnosis and comorbidities was included to provide a broad picture of experienced barriers and facilitators.

Although common in qualitative interview studies, the results might lack generalizability and completeness. Despite heterogeneity of the participant group, the sample size was small, and lacked diversity in for instance cultural differences, cognitive abilities and (in)experience in discussing mental health problems. Another limitation is the retrospective design of the study, which can be affected by inaccuracy or incompleteness of recollection (42). Finally, service users differed in reflective abilities, and together with recall bias, this may have resulted in missing some information. Future (quantitative) studies might take into account these limitations.

\section{Clinical implications}

An important implication for clinical practice is that healthcare providers should be aware of possible additional limitations service users experience in identifying and discussing mental health problems. In addition, they should understand their influence on service users' acknowledgement of and willingness to discuss mental health issues. GPs' knowledge on VI and overall healthcare providers' knowledge on the impact of VI on mental health should be increased. Moreover, standard procedures could be introduced, with a screening instrument as a routine part of care. This might facilitate healthcare providers to start a conversation about the impact of VI on mental health. Finally, healthcare providers could actively provide information about depression and anxiety, in a way that is suitable for adults with VI (verbally, digitally or in Braille) to increase health literacy. 


\section{Conclusion}

This study revealed important factors related to the detection and discussion of depression and anxiety in adults with VI from the service users' perspective. The results suggest that an increased vulnerability of adults with $\mathrm{VI}$, concerning difficulty acknowledging both their $\mathrm{VI}$ and mental health problems, low health literacy, difficulty of attributing symptoms to the right impairment and reluctance to discuss symptoms, complicates identifying and discussing mental health problems. As for many other things in life, this greatly increases their dependency on others. Both the social support system and healthcare providers can play an important role in eliminating these barriers. Insights from this study could facilitate training for healthcare providers and improve detection of depression and anxiety in adults with VI. Ultimately, this might improve quality of care and subsequently the service users' quality of life.

\section{Abbreviations}

GP: general practitioner

SD: standard deviation

Vl: visual impairment

\section{Declarations}

\section{Ethics approval and consent to participate}

The study protocol was approved by the Medical Ethics Committee (METc) of Amsterdam University Medical Centers (UMC), location VUmc, the Netherlands. The METc VUmc issues nationally valid judgements. The study was performed according the standards of the Declaration of Helsinki (1964) and its later amendments. Written informed consent was obtained from all individual participants included in the study.

\section{Consent for publication}

Not applicable.

\section{Availability of data and material}

The data that support the findings of this study are available on reasonable request from the corresponding author. The data are not publicly available due to their containing information that could compromise the privacy of research participants. Interview guidelines are included as supplementary material.

\section{Competing interests}

The authors have no conflicts of interest to declare that are relevant to the content of this article.

\section{Funding}

This work was supported by the 'Programmaraad'; a Dutch funding group from the low vision service 
organizations Royal Dutch Visio, Bartiméus and the Robert Coppes Foundation. The sponsor had no role in the design and conduct of this study or in the writing of the manuscript.

\section{Authors' contributions}

HvdA, PV and RvN were involved in funding acquisition and contributed to the study conception and design. EvM and HvdA developed the interview scheme. Data collection was performed by EvM and analysis were performed by EvM and HvdA. The first draft of the manuscript was written by EvM and all authors commented on previous versions of the manuscript. All authors read and approved the final manuscript.

\section{Acknowledgements}

We would like to thank all participating adults and the 'Programmaraad' for making this study possible.

\section{References}

1. van der Aa HPA, Comijs HC, Penninx BWJH, van Rens GHMB, van Nispen RMA. Major depressive and anxiety disorders in visually impaired older adults. Invest Ophthalmol Vis Sci. 2015;56(2):849-54.

2. Horowitz A, Reinhardt JP, Kennedy GJ. Major and subthreshold depression among older adults seeking vision rehabilitation services. Am J Geriatr Psychiatry. 2005;13(3):180-7.

3. Renaud J, Bedard E. Depression in the elderly with visual impairment and its association with quality of life. Clin Interv Aging. 2013;8:931-43.

4. van der Aa HP, Margrain TH, van Rens GH, Heymans MW, van Nispen RM. Psychosocial interventions to improve mental health in adults with vision impairment: systematic review and meta-analysis. Ophthalmic Physiol Opt. 2016;36(5):584-606.

5. van der Aa HP, Hoeben M, Rainey $L$, van Rens $G H$, Vreeken $H L$, van Nispen RM. Why visually impaired older adults often do not receive mental health services: the patient's perspective. Qual Life Res. 2015;24(4):969-78.

6. Nollett CL, Bray N, Bunce C, Casten RJ, Edwards RT, Hegel MT, et al. High prevalence of untreated depression in patients accessing low-vision services. Ophthalmology. 2016;123(2):440-1.

7. Holloway EE, Sturrock BA, Lamoureux EL, Keeffe JE, Rees G. Depression screening among older adults attending low-vision rehabilitation and eye-care services: Characteristics of those who screen positive and client acceptability of screening. Australas J Ageing. 2015;34(4):229-34.

8. Fenwick EK, Lamoureux EL, Keeffe JE, Mellor D, Rees G. Detection and management of depression in patients with vision impairment. Optom Vis Sci. 2009;86(8):948-54.

9. Nollett C, Bartlett R, Man R, Pickles T, Ryan B, Acton JH. How do community-based eye care practitioners approach depression in patients with low vision? A mixed methods study. BMC Psychiatry. 2019;19(1):426.

10. Rees G, Fenwick EK, Keeffe JE, Mellor D, Lamoureux EL. Detection of depression in patients with low vision. Optom Vis Sci. 2009;86(12):1328-36. 
11. Callahan CM, Unverzagt FW, Hui SL, Perkins AJ, Hendrie HC. Six-item screener to identify cognitive impairment among potential subjects for clinical research. Med Care. 2002;40(9):771-81.

12. de Vries H, Mudde A, Leijs I, Charlton A, Vartiainen E, Buijs G, et al. The European Smoking Prevention Framework Approach (EFSA): an example of integral prevention. Health Educ Res. 2003;18(5):61126.

13. Knops-Dullens T, de Vries N, de Vries H. Reasons for non-attendance in cervical cancer screening programmes: an application of the Integrated Model for Behavioural Change. Eur J Cancer Prev. 2007;16(5):436-45.

14. Segaar D, Bolman C, Willemsen M, De Vries H. Identifying determinants of protocol adoption by midwives: a comprehensive approach. Health Educ Res. 2007;22(1):14-26.

15. Pope C, Ziebland S, Mays N. Qualitative research in health care. Analysing qualitative data. BMJ. 2000;320(7227):114-6.

16. Lindgren CL, Burke ML, Hainsworth MA, Eakes GG. Chronic sorrow: a lifespan concept. Sch Inq Nurs Pract. 1992;6(1):27-40; discussion 1-2.

17. Verhaak PF, Prins MA, Spreeuwenberg P, Draisma S, van Balkom TJ, Bensing JM, et al. Receiving treatment for common mental disorders. Gen Hosp Psychiatry. 2009;31(1):46-55.

18. Wittkampf KA, van Zwieten M, Smits FT, Schene AH, Huyser J, van Weert HC. Patients' view on screening for depression in general practice. Fam Pract. 2008;25(6):438-44.

19. Schnyder N, Panczak R, Groth N, Schultze-Lutter F. Association between mental health-related stigma and active help-seeking: systematic review and meta-analysis. Br J Psychiatry. 2017;210(4):261-8.

20. Southall K, Wittich W. Barriers to Low Vision Rehabilitation: A Qualitative Approach. Journal of Visual Impairment \& Blindness. 2012;106(5):261-74.

21. Mittal D, Sullivan G, Chekuri L, Allee E, Corrigan PW. Empirical Studies of Self-Stigma Reduction Strategies: A Critical Review of the Literature. Psychiatr Serv. 2012;63(10):974-81.

22. Prins MA, Verhaak PF, Bensing JM, van der Meer K. Health beliefs and perceived need for mental health care of anxiety and depression-the patients' perspective explored. Clin Psychol Rev. 2008;28(6):1038-58.

23. van Beljouw I, Verhaak P, Prins M, Cuijpers P, Penninx B, Bensing J. Reasons and determinants for not receiving treatment for common mental disorders. Psychiatr Serv. 2010;61(3):250-7.

24. Harrison TC, Mackert M, Watkins C. Health literacy issues among women with visual impairments. Res Gerontol Nurs. 2010;3(1):49-60.

25. Warren M, DeCarlo DK, Dreer LE. Health Literacy in Older Adults With and Without Low Vision. Am J Occup Ther. 2016;70(3):7003270010.

26. Ratzan S, Parker R, Selden C, Zorn M. National library of medicine current bibliographies in medicine: health literacy. Bethesda, MD: National Institutes of Health, US Department of Health and Human Services. 2000. 
27. O'Connor M, Casey L. The Mental Health Literacy Scale (MHLS): A new scale-based measure of mental health literacy. Psychiatry Res. 2015;229(1-2):511-6.

28. Lamoureux EL, Hassell JB, Keeffe JE. The determinants of participation in activities of daily living in people with impaired vision. Am J Ophthalmol. 2004;137(2):265-70.

29. O'Conor R, Smith SG, Curtis LM, Benavente JY, Vicencio DP, Wolf MS. Mild Visual Impairment and Its Impact on Self-Care Among Older Adults. J Aging Health. 2018;30(3):327-41.

30. Schakel W, Bode C, Elsman EBM, van der Aa HPA, de Vries R, van Rens G, et al. The association between visual impairment and fatigue: a systematic review and meta-analysis of observational studies. Ophthalmic Physiol Opt. 2019;39(6):399-413.

31. Sturrock BA, Xie J, Holloway EE, Lamoureux EL, Keeffe JE, Fenwick EK, et al. The Influence of Coping on Vision-Related Quality of Life in Patients With Low Vision: A Prospective Longitudinal Study. Invest Ophthalmol Vis Sci. 2015;56(4):2416-22.

32. Aldwin CM, Revenson TA. Does coping help? A reexamination of the relation between coping and mental health. J Pers Soc Psychol. 1987;53(2):337-48.

33. Cimarolli VR, Boerner K, Reinhardt JP, Horowitz A, Wahl HW, Schilling O, et al. A population study of correlates of social participation in older adults with age-related vision loss. Clin Rehabil. 2017;31(1):115-25.

34. Papadopoulos K, Montgomery AJ, Chronopoulou E. The impact of visual impairments in self-esteem and locus of control. Res Dev Disabil. 2013;34(12):4565-70.

35. Maaswinkel IM, van der Aa HPA, van Rens G, Beekman ATF, Twisk JWR, van Nispen RMA. Mastery and self-esteem mediate the association between visual acuity and mental health: a populationbased longitudinal cohort study. BMC Psychiatry. 2020;20(1):461.

36. Kahn R, Antonucci T. Convoys Over the Life Course: Attachment Roles and Social Support. 31980. p. 253-67.

37. Polacsek M, Boardman GH, McCann TV. Help-seeking experiences of older adults with a diagnosis of moderate depression. Int J Ment Health Nurs. 2019;28(1):278-87.

38. Cimarolli VR, Boerner K. Social Support and Well-being in Adults who are Visually Impaired. Journal of Visual Impairment \& Blindness. 2005;99(9):521-34.

39. Percival J, Hanson J. 'I'm Like a Tree a Million Miles from the Water's Edge': Social Care and Inclusion of Older People with Visual Impairment. The British Journal of Social Work. 2005;35(2):189-205.

40. Goodman CR, Shippy RA. Is it contagious? Affect similarity among spouses. Aging Ment Health. 2002;6(3):266-74.

41. Braich PS, Jackson M, Knohl SJ, Bhoiwala D, Gandham SB, Almeida D. Burden and Depression in Caregivers of Blind Patients in New York State. Ophthalmic Epidemiol. 2016;23(3):162-70.

42. Porta M, Last JM. A Dictionary of Public Health: Oxford University Press; 20182018. 


\section{Supplementary Files}

This is a list of supplementary files associated with this preprint. Click to download.

- vanMunsterAdditionalfile1DepressionAnxietyVisuallmpairment.docx

- vanMunsterAdditionalfile1DepressionAnxietyVisuallmpairment.docx 